\title{
CARDIACTAMPONADE DURING THE EVOLUTION OF SYSTEMIC LUPUS ERYTHEMATOSUS IN MALE: CASE REPORT
}

Débora Rocha de Moura Rodrigues de Aguiar ${ }^{1,2^{*}}$, Isabela Mayume Mariussi Takahashi², Ana Júlia Nicoliello Dias², Luiz Henrique dos Santos Araujo ${ }^{1}$, Elba Sophia Theodoro Santos de Oliveira ${ }^{1,2}$, Luiz Felipe Dipe Prates Miranda ${ }^{1,2}$

1. Hospital Federal de Bonsucesso, Rio de Janeiro (RJ), Brazil. 2. Universidade do Grande Rio, Duque de Caxias (RJ), Brazil.

*Corresponding author: deboramouraaguiar@gmail.com

\section{BACKGROUND}

Systemic lupus erythematosus (SLE) is an autoimmune disease with female:male prevalence is 9:1. For this reason, diagnosis in patients who differ the classic epidemiology, such as SLE in men, is often difficult to make. Although pericarditis and pericardial effusion are common cardiac complications of SLE, cardiac tamponade (CT) is a rare manifestation of this disease, usually described in the presentation and in women. In a previously Brazilian report, CT was observed in $1.23 \%$ of patients, 4/325 patients and three of them were women.

\section{CASE REPORT}

52-year-old male admitted with a began in October 2018 with history of arthralgia, fever, weight loss, adynamia, and skin lesions. Biopsy showed perivascular lymphocytic infiltrate associated with an erasure of the basal layer of the epidermis, compatible with SLE. During the investigation, when performing echocardiogram for anasarca investigation, a volume pericardial spill was observed with right ventricle restriction. He underwent emergency pericardiocentesis on August 14, 2019 and pericardial biopsy, whose results were pericardial spill with typical and reactive mesothelial cells, connective stroma with congestion. He had previous examinations with antinuclear antibody (ANA) 1/640 stippled and positivity in autoantibodies: Anti-Sm, Anti-Ro; Anti-RNP and low complement: C3 $21 \mathrm{mg} / \mathrm{dL}$ and C4 $2 \mathrm{mg} / \mathrm{dl}$. He had IgG and IgM positive dengue serology, chikungunya and zika, hepatitis B negative and anti-HCV positive, C-reactive protein (CRP) being performed for positive viral RNA. The cryoglobulin research was negative. The patient had $1.6 \mathrm{~g}$ of protein in the urine in July 2019 that increased to $4 \mathrm{~g}$ in September 2019. Renal biopsy was performed and showed lupus nephritis class IV, without signs of chronicity. He was diagnosed with SLE because he had 4 clinical criteria: acute cutaneous lupus, synovitis in wrists, elbow and knees, renal with $4 \mathrm{~g}$ of protein/24 $\mathrm{h}$, pericardium effusion. Besides that, he had 3 immunological criteria for SLE: ANA, anti-DNA, low complement. He is currently using mycophenolate $3 \mathrm{~g} /$ day (induction dose), hydroxychloroquine $5 \mathrm{mg} / \mathrm{kg}$ once daily. There was a significant improvement in the patient's anemia and kidney function.

\section{CONCLUSION}

Systemic lupus erythematosus is a heterogenous and potentially serious disease, with highly variable clinical manifestations. Cardiac tamponade is a rare manifestation, usually described at the diagnosis of SLE. In our case, the CT happened during the course of the case, differently from the descriptions in the literature, and in a man. The biopsy was compatible with lupus associated serositis, excluding another differential diagnosis. The authors declare that the patient was oriented and signed the written informed consent form. 